\title{
XLVII. Experimental determination of the beats in the vibrations of a revolving bell
}

\author{
James Walker M.A. \& J. L. S. Hatton B.A.
}

To cite this article: James Walker M.A. \& J. L. S. Hatton B.A. (1891) XLVII. Experimental determination of the beats in the vibrations of a revolving bell, Philosophical Magazine Series 5, 32:197, 370-374, DOI: 10.1080/14786449108620198

To link to this article: http://dx.doi.org/10.1080/14786449108620198

曲 Published online: 08 May 2009.

Submit your article to this journal $\sqsubset \pi$

Џ Article views: 2

Q View related articles $匚$ 
melting-point phosphorus, while curve (4) shows the rate of cooling of the other variety: both these curves are for the cooling of equal quantities of phosphorus. It will be seen that there is an appreciable difference in the heat given out; and this toois to a great extent masked, as the rhombic modification, on solidifying without cooling previously to below its solidification-point, is converted to a great extent into the octahedral modification. This is also the reason why both modifications solidify at the same temperature, viz. $43^{\circ} \cdot 8$. This temperature may therefore be taken as the solidifyingpoint of the octahedral modification, while that of the other variety is not known. It must, however, be a temperature below and not above this point. In order to determine it accurately, it would be necessary to cool a very large quantity of liquid phosphorus to below this temperature and then carse it to solidify, and notice the temperature to which the thermometer rushed up. If only a moderate quantity of phosphorus, as fifty grams, were thus treated, the heat of solidification would not be sufficient to raise the temperature of the mass up to the true temperature of solidification.

The different properties of the two modifications of phosphorus may be summed up as follows :-

Octahedral modification.

Has definite melting-point at $44^{\circ} 3$.

Specific gravity at $13^{\circ}, 1 \cdot 8177$.

Has considerably greater latent heat of fusion than rhombic variety.

Formed from the rhombic variety by cooling rapidly.

Solidifies at $43^{\circ} \cdot 8$.

The University Laboratory, Oxford.

\section{Rhombic modificution.}

Has no well-defined meltingpoint: melts at about $45^{\circ} \cdot 3$.

Specific gravity at $13^{\circ}, 1.827^{\circ}$.

Has less latent heat of fusion than octahedral variety, and it begins to absorb this at about $38^{\circ}$.

Formed from the octahedral variety by cooling slowly, so that it cools below the solidification-point before solidification sets in.

XLVII. Experimental Determination of the Beats in the Viltrations of a Revolving Bell. By JAMES W ALKER, M.A., and J. L. S. Hatton, B.A., Demonstrators at the Clarendon Laboratory, Oxford*.

TN a communication read before the British Association 1 at Leeds, and in a paper published in the Proceedings of the Cambridge Philosophical Society (vol. vii. p. 101)

* Communicated by the Authors. 
Mr. G. H. Bryan has given the mathematical theory of the rotation of the nodal meridians in a revolving cylinder or beil. According to his analysis, the number of beats per revolution due to this rotation of the nodal meridians is independent of the velocity of revolution, and is given in the case of twodimensional oscillations by $2 s\left(s^{2}-1\right) /\left(s^{2}+1\right), 2 s$ being the number of nodal meridians, and in the general case by $2 s\left(s^{2}+\lambda_{s}-1\right) /\left(s^{2}+\lambda_{s}+1\right), \quad \lambda_{s}$ being a quantity which can never be negative.

Mr. Bryan's own experiments with two different champagneglasses gave "about $2 \cdot 6$ and $2 \cdot 2$ beats per revolution respectively for the gravest tone," of which "the latter is too small to be compatible with" the theory, and it was at his suggestion that we have undertaken some experiments at the Clarendon Laboratory in order to test the same. The results already obtained appear of sufficient interest to warrant this preliminary note on the subject, pending a fuller investigation with more accurate apparatus.

The glass to be experimented upon was rigidly attached to the disk of a whirling-table carrying a graduated scale; and an index, which could be held in a fixed position in space, was carried round with the disk when released by the observer. The glass was caused to vibrate by means of a bow : when the note obtained was free from beats and of the required pitch the disk was rotated. In order to prevent complicating the experiment by the acceleration of the disk several beats were first observed, and when the intervals at which they occurred appeared to be uniform the index was released on hearing a beat, and after the observation of a certain number the disk was stopped. The whole number of turns were counted, and the position of the index when the disk was stopped gave the fraction of a turn.

In order to concentrate the sound and to prevent any motion of the ear during the observations, the beats were observed through a tube fixed with one extremity close to the revolving glass. A difficulty arose in obtaining glasses which gave a pure tone, and it was found that, even after careful selection of the glass, accuracy was only to be arrived at when the vibrations were excited with great care by means of a violin-bow. The glasses selected were bell-shaped.

The following were the results obtained, and it will be observed that in each case the mean is slightly above the value calculated from the two-dimensional theory. 
372 Messrs. Walker and Hatton on the Determination of Glass No. 1. Gravest tone $c^{\prime \prime \prime}$.

\begin{tabular}{|c|c|c|c|}
\hline & Beats. & Revolutions. & $\begin{array}{c}\text { Beats per } \\
\text { Revolution. }\end{array}$ \\
\hline Four nodes. & $\begin{array}{l}14 \\
14 \\
16 \\
10 \\
8 \\
10 \\
10 \\
12 \\
11 \\
17\end{array}$ & $\begin{array}{l}5 \cdot 65 \\
5 \cdot 7 \\
6 \cdot 5 \\
4 \cdot 0 \\
3 \cdot 225 \\
4 \cdot 0 \\
4 \cdot 1 \\
4 \cdot 77 \\
4 \cdot 38 \\
7 \cdot 0\end{array}$ & $\begin{aligned} 2 \cdot 48 \\
2 \cdot 46 \\
2 \cdot 46 \\
2 \cdot 5 \\
2 \cdot 48 \\
2 \cdot 5 \\
2 \cdot 44 \\
2 \cdot 52 \\
2 \cdot 51 \\
2 \cdot 43 \\
\text { Mean... } 2 \cdot 48\end{aligned}$ \\
\hline Six nodes. & $\begin{array}{r}8 \\
8 \\
8 \\
9 \\
8 \\
8 \\
10 \\
10 \\
10 \\
8\end{array}$ & $\begin{array}{l}1 \cdot 65 \\
1.64 \\
1.6 \\
1.87 \\
1.65 \\
1 \cdot 65 \\
2 \cdot 08 \\
2 \cdot 1.2 \\
2 \cdot 1 \\
1 \cdot 65\end{array}$ & $\begin{array}{r}4 \cdot 85 \\
4 \cdot 88 \\
5 \cdot 0 \\
4 \cdot 81 \\
4 \cdot 85 \\
4 \cdot 85 \\
4 \cdot 81 \\
4 \cdot 72 \\
4 \cdot 76 \\
4 \cdot 85 \\
\\
\text { Mean... } 4 \cdot 84\end{array}$ \\
\hline Eight nodes. & $\begin{array}{l}8 \\
8 \\
8 \\
4 \\
8 \\
8 \\
8 \\
8 \\
8 \\
8\end{array}$ & $\begin{array}{l}1.08 \\
1 \cdot 14 \\
1 \cdot 1 \\
1 \cdot 13 \\
1 \cdot 1 \\
1 \cdot 12 \\
1 \cdot 1.2 \\
1.05 \\
1.08 \\
1.08\end{array}$ & $\begin{array}{r}7 \cdot 41 \\
7 \cdot 01 \\
7 \cdot 27 \\
7 \cdot 08 \\
7 \cdot 27 \\
7 \cdot 14 \\
7 \cdot 14 \\
7 \cdot 62 \\
7 \cdot 41 \\
7 \cdot 41 \\
\text { Mean... } 7 \cdot 28\end{array}$ \\
\hline
\end{tabular}

\begin{tabular}{|c|c|c|c|}
\hline \multirow{2}{*}{ Number of Nodes. } & \multicolumn{2}{|c|}{ Beats per Revolution. } & \multirow{2}{*}{ Difference. } \\
\cline { 2 - 3 } & Theory. & Experiment. & \\
\hline 4 & $2 \cdot 4$ & $2 \cdot 48$ & .08 \\
6 & $4 \cdot 8$ & $4 \cdot 84$ & .04 \\
8 & $7 \cdot 005$ & $7 \cdot 28$ & .275 \\
\hline
\end{tabular}


the Beats in the Vibrations of a Revolving Bell. 373

Glass No. 2. Gravest Tone $g^{\prime \prime}$.

\begin{tabular}{|c|c|c|c|}
\hline & Beats. & Revolutions. & $\begin{array}{l}\text { Beats per } \\
\text { Revolution. }\end{array}$ \\
\hline Four nodes. & $\begin{array}{r}9 \\
11 \\
12 \\
9 \\
12 \\
17 \\
14 \\
15 \\
11 \\
12\end{array}$ & $\begin{array}{l}3 \cdot 75 \\
4 \cdot 49 \\
4 \cdot 92 \\
3 \cdot 73 \\
4 \cdot 87 \\
6 \cdot 97 \\
5 \cdot 59 \\
6 \cdot 27 \\
4 \cdot 47 \\
5 \cdot 03\end{array}$ & $\begin{array}{r}2 \cdot 4 \\
2 \cdot 45 \\
2 \cdot 44 \\
2 \cdot 41 \\
2 \cdot 46 \\
2 \cdot 44 \\
2 \cdot 5 \\
2 \cdot 39 \\
2 \cdot 46 \\
2 \cdot 38 \\
\text { Mean... } 2 \cdot 43\end{array}$ \\
\hline Six nodes. & $\begin{array}{r}11 \\
13 \\
10 \\
10 \\
9 \\
7 \\
8 \\
11 \\
9 \\
9\end{array}$ & $\begin{array}{l}2 \cdot 29 \\
2.38 \\
2 \cdot 12 \\
2 \cdot 1 \\
1 \cdot 87 \\
1.45 \\
1 \cdot 66 \\
2 \cdot 26 \\
1 \cdot 84 \\
1 \cdot 88\end{array}$ & $\begin{array}{r}4 \cdot 8 \\
5 \cdot 04 \\
4 \cdot 71 \\
4 \cdot 76 \\
4 \cdot 81 \\
4 \cdot 83 \\
4.82 \\
4.87 \\
4.89 \\
4.79 \\
\text { Mean... } 4.83\end{array}$ \\
\hline Eight nodes. & $\begin{array}{l}12 \\
15 \\
14 \\
13 \\
15 \\
14 \\
15 \\
15 \\
13 \\
19\end{array}$ & $\begin{array}{l}1 \cdot 64 \\
2 \cdot 11 \\
1 \cdot 99 \\
1 \cdot 88 \\
2 \cdot 08 \\
1.94 \\
2.05 \\
1 \cdot 67 \\
1 \cdot 86 \\
2 \cdot 69\end{array}$ & $\begin{array}{r}7.82 \\
7.11 \\
7.08 \\
6.91 \\
7.21 \\
7.22 \\
7.32 \\
7 \cdot 18 \\
6.99 \\
7.06 \\
\text { Mean... } \\
7.15\end{array}$ \\
\hline
\end{tabular}

\begin{tabular}{|c|c|c|c|}
\hline \multirow{2}{*}{ Number of Nodes. } & \multicolumn{2}{|c|}{ Beats per Revolution. } & Difference. \\
& Theory. & Experiment. & \\
\hline 4 & $2 \cdot 4$ & $2 \cdot 43$ & $\cdot 03$ \\
6 & 4.8 & $4 \cdot 83$ & .03 \\
8 & 7.005 & $7 \cdot 13$ & $\cdot 125$ \\
\hline
\end{tabular}


These results afford, moreover, the means of determining in the case of a non-revolving bell the proportion of the whole kinetic energy which is due to the longitudinal components of the displacement, and thus give an indication of the extent to which the vibrations differ from two-dimensional vibrations on the one hand (in which the proportion is zero), and from the vibrations of a circular plate on the other hand (in which the proportion is unity).

For, according to Mr. Bryan's results, the kinetic energy in the case of a non-revolving bell is proportional to $\left(\lambda_{s}+1+s^{2}\right) p^{2}$, in which expression the term $\lambda_{s} p^{2}$ arises from the longitudinal motion, and hence the proportion in question is

$$
\frac{\lambda_{s}}{\lambda_{s}+\overline{1}+s^{2}}
$$

On the other hand, when the bell is rotated the number of beats per revolution is

$$
2 s \frac{\lambda_{s}+s^{2}-1}{\lambda_{s}+s^{2}+1}=n \text { say, }
$$

whence we easily obtain

$$
\frac{\lambda_{s}}{\lambda_{s}+1+s^{2}}=\frac{n\left(s^{2}+1\right)-2 s\left(s^{2}-1\right)}{4 s} .
$$

Using the values given above for the number of beats per revolution in the case of the different modes of vibration of the two glasses, we obtain from the above formula the following results :-

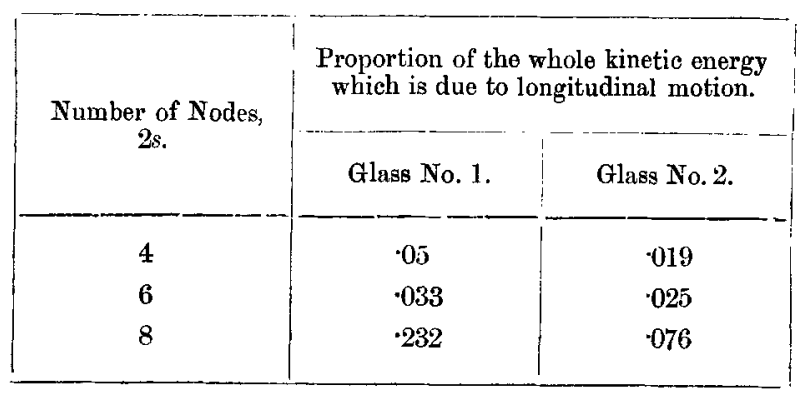

